\title{
0 pensamento geoestratégico e os documentos estratégicos dos Estados Unidos no pós Guerra Fria
}

\author{
Geostrategic thinking and strategic documents \\ of the United States in the post-Cold War
}

DOI: $10.21530 /$ ci.v13n2.2018.808

Raphael Padula ${ }^{1}$

\section{Resumo}

O propósito do artigo é mostrar que há uma conexão entre o pensamento geopolítico clássico anglo-saxão (Mahan, Mackinder e Spykman), as formulações geoestratégicas de Brzezinski e Kissinger durante a Guerra Fria e o pós Guerra Fria, e os documentos estratégicos dos Estados Unidos nesse último período. Essa hipótese é comprovada através da prioridade atribuída à Eurásia (relações Leste-Oeste, no hemisfério Norte), mudando somente a intensidade de atuação em suas diferentes áreas em função da conjuntura histórica. Ao mesmo tempo, não se deixa de atentar para uma geoestratégia permanente de supremacia na América (hemisfério Ocidental). A pesquisa se apoia em bibliografia original dos autores abordados e na análise de documentos estratégicos selecionados de todos os governos estadunidenses na era pós Guerra Fria entre 1991-2016 (Bush a Obama).

Palavras-chave: Estados Unidos; Geopolítica; Geoestratégia; Eurásia; OTAN.

\section{Abstract}

The papers' goal is to show the connection between the classical Anglo-Saxon geopolitical thought (Mahan, Mackinder and Spykman), the geostrategic formulations of Brzezinski and Kissinger during the Cold War and the Post Cold War era, and the United States strategic documents in this latter period. Such hypothesis is proved by the priority given to Eurasia

1 Coordenador e Professor Permanente da Pós-Graduação em Economia Política Internacional (PEPI) do Instituto de Economia (IE/UFRJ), Professor Adjunto da Universidade Federal do Rio de Janeiro (UFRJ) da área de Economia Política Internacional, da graduação de Relações Internacionais. Economista pelo IE/UFRJ (2004), Mestre (2005) e Doutor (2010) em Engenharia de Produção pela COPPE-UFRJ. Editor da revista Oikos — Revista de Economia Política Internacional. Membro do grupo de pesquisa "Poder Global e Geopolítica do Capitalismo".

Artigo submetido em 24/05/2018 e aprovado em 23/08/2018. 
(East-West relations in the Northern Hemisphere), changing only the intensity of action in its different areas in due to historical conjuncture. At the same time, a permanent geostrategy of supremacy in America (Western Hemisphere) is also regarded. The research is based on the original bibliography of the authors and the analysis of selected strategic documents from all US governments in the Post Cold War between 1991-2016 (Bush to Obama).

Keywords: United States, Geopolitics, Geoestrategy, Eurasia, NATO.

O homem de Estado que conduz a política externa só pode tomar em conta os valores de justiça, equidade e tolerância na medida em que contribuam ao objetivo de poder ou enquanto não interfiram nele. Pode utilizá-los como instrumentos que desde o ponto de vista moral justifiquem a aspiração de poder, porém deve rechaçá-los no instante em que sua aplicação se traduza em debilidade. Não se busca o poder para o alcance de valores morais, porém se utilizam os valores morais para facilitar a aquisição de poder.

(Spykman, 1942, p. 26, tradução nossa) ${ }^{2}$

\section{Introdução}

O eixo geográfico de orientação para a geoestratégia dos Estados Unidos é um tema fundamental no seu debate pós Guerra Fria. Quais seriam as relações fundamentais para os EUA? Norte-Sul, centrada no hemisfério ocidental ou América? Ou Leste-Oeste, centrada no hemisfério Norte ou nas relações da América do Norte com a Eurásia (KAPLAN, 2015)? Ao mesmo tempo, a dimensão ética aparece permanentemente nos debates sobre política externa dos EUA (ANDERSON, 2015).

$\mathrm{O}$ argumento central do artigo é de que há uma conexão entre o pensamento geopolítico clássico anglo-saxão (Mahan, Mackinder e Spykman), as formulações geoestratégicas de Brzezinski e Kissinger durante a Guerra Fria e o pós Guerra Fria, e os documentos estratégicos dos EUA nesse último período, até o governo Barack Obama (1991-2016). A hipótese principal é de que tal conexão se comprova através da prioridade atribuída à Eurásia (relações Leste-Oeste no hemisfério Norte), mudando somente a intensidade de atuação em diferentes áreas do continente em

2 "The statesman who conducts foreign policy can concern himself with values of justice, fairness, and tolerance only in the extent that they contribute to or do not interfere with the power objective. They can be used instrumentally as moral justification for the power quest, but they must be discarded the moment their application brings weakness. The search for power is not made for the achievement of moral values; moral values are used to facilitate the attainment of power". 
função da conjuntura histórica. Ao mesmo tempo, não se deixa de atentar para uma geoestratégia permanente de supremacia na América (hemisfério ocidental). A pesquisa se apoia em bibliografia original dos autores abordados e na análise de documentos estratégicos selecionados de todos os governos estadunidenses na era pós Guerra Fria. Kissinger e Brzezinski foram selecionados em razão de sua influência no debate geoestratégico e nos governos dos partidos Republicano e Democrata, respectivamente.

Vale ressaltar que, no debate geoestratégico estadunidense, tais posições se diferenciam de autores que defendem uma menor ou mesmo retirada da participação dos EUA na Eurásia (e na OTAN), como Mearsheimer e Walt (2016), no primeiro caso, ou Huntington (2005) e Kaplan (2015), no segundo - que defendem que a principal ameaça aos EUA viria de suas relações com o hemisfério ocidental, ou do México, em particular. No entanto, por razões de escopo e espaço, esse debate não será objeto desse artigo.

Para cumprir seu objetivo, o artigo se divide em 5 seções, além da introdução. A primeira resume a posição dos autores da geopolítica clássica anglo-saxã. A segunda sintetiza as visões de Brzezinski e Kissinger sobre a Guerra Fria. A terceira aborda a visão dos mesmos autores para a era pós Guerra Fria. A quarta seção apresenta uma análise dos documentos estratégicos selecionados. A última seção apresenta as considerações finais.

\section{A geopolítica clássica: centralidade da Eurásia e hegemonia hemisférica}

Mesmo antes da formação de um pensamento geopolítico, um dos paisfundadores dos EUA, Alexander Hamilton (1787), em um dos seus artigos que formaram os Federalist Papers, aponta que da união das treze colônias emergiria um grande sistema capaz de equilibrar as relações de poder no Atlântico Norte e ditar os termos das relações entre o Velho e o Novo Mundo. A Doutrina Monroe, anunciada pelo presidente estadunidense ao congresso em 1823, explicitou a preocupação com a projeção de potências externas no hemisfério ocidental, e assim o perímetro de segurança dos EUA.

Mais especificamente, o debate da geopolítica clássica, especialmente os autores da escola anglo-saxã, trouxeram importantes contribuições para a formulação da geoestratégia estadunidense, assim como para o seu debate atual. Ao estudar a 
evolução do domínio marítimo britânico como a fonte de sua supremacia global, o almirante estadunidense Mahan (1890) salienta a importância do domínio de ilhas transoceânicas, de passagens estratégicas e portos continentais para o controle de rotas marítimas estratégicas. Na verdade, esse é um dos pilares da política externa britânica, desde que abandonou sua política de tentar se expandir pelo continente europeu, após a guerra dos Cem Anos (1337-1453) contra a França. Ao pregar a necessidade do desenvolvimento do poder naval estadunidense, Mahan prescreveu como imprescindível no curto prazo o domínio do Mar do Caribe e do Golfo do México, assim como a construção de um canal transoceânico no istmo do Panamá sob o controle estadunidense, para que suas marinhas de guerra e mercante auferissem maior capacidade de mobilidade entre os oceanos Atlânticos e Pacífico, proporcionando maior segurança territorial e maior expansão produtiva-industrial e comercial. Assim, o autor justificou o imperialismo dos EUA na América Latina por questões de segurança e de expansão industrial-comercial. Ainda, no médio prazo, apontou que os EUA deveriam controlar o triângulo Panamá-Havaí-Alaska, para sua segurança no Pacífico, e emergir como um grande poder no Atlântico Norte.

Já o geógrafo britânico Mackinder (1904), ao formular sua teoria da supremacia do poder terrestre, apontou a Eurásia como o continente basilar para o equilíbrio ou disputa de poder global, por razões materiais: massa territorial, população, recursos econômicos e industriais e poder militar. Na sua visão, o Estado (ou aliança) que dominasse a Eurásia controlaria os rumos da política mundial. Na verdade, olhando para um autêntico domínio terrestre exercido pela Rússia na área central da Eurásia, e ainda vislumbrando a possibilidade de domínio ou aliança com a Alemanha na área central da Europa, o autor colocou em evidência um dos pilares da política externa britânica, praticados desde a contenção da expansão do Império Habsburgo nos séculos XV-XVI: estabelecer um poder dividido e equilibrado na Eurásia, sem deixar que nenhuma potência ou aliança alcance a supremacia. Ou ainda, o princípio da política de contenção nas bordas da Eurásia, para evitar que o poder terrestre se torne anfíbio.

Mas foi Spykman (1942) que sintetizou a geoestratégia estadunidense, partindo de sua posição geográfica. O autor a um só tempo justifica o intervencionismo (e a preocupação com o equilíbrio de poder) na Eurásia e a hegemonia no hemisfério ocidental. Spykman observa um paralelismo geográfico entre a América do Norte e a Eurásia, por terem a mesma vizinhança (Atlântico, Pacífico e Mar Ártico) e, portanto, se cercarem mutuamente, estando próximas e interligadas por 
ilhas transoceânicas - ainda mais com o avanço do poder aéreo e das tecnologias que proporcionam maior raio de alcance para a agressão militar. Assim, os EUA seriam uma ilha transoceânica cercada pelas extremidades da Eurásia e deveria atuar permanentemente nessa área geográfica para promover seu equilíbrio de poder, além de dominar as ilhas transatlânticas e transpacíficas. Não interessaria uma federação da Europa formando um único ator com supremacia na região. Na América, hemisfério ocidental, a supremacia estadunidense não poderia ser ameaçada, dentro do seu objetivo mais amplo de segurança; não só na "América Mediterrânea” (Mar do Caribe e Golfo do México, incluindo Venezuela e Colômbia), mas também na "zona equidistante meridional" ao sul do Amazonas, para utilizar as referências espaciais de Spykman. Por haver um desequilíbrio de poder tão grande e revelado, e também pela proximidade e continuidade geográfica, a política estadunidense deveria ser de hegemonia, promovendo a permanente dependência política de seus Estados, e afastando a projeção e alianças de potências externas. Sobretudo, seria necessário dispor de seus recursos e territórios estratégicos por razões de segurança, formando um sistema autárquico, caso alguma potência ou aliança viesse a dominar a Eurásia.

\section{Brzezinski e Kissinger: a geoestratégia na Guerra Fria}

A Geopolítica de Contenção à expansão e à influência da União Soviética praticada pelos EUA durante a Guerra Fria, formulada por George Kennan em seu "longo telegrama" e colocada em ação inicialmente pela Doutrina Truman, seguiram a ideia de que a Eurásia seria o continente basilar na disputa de poder global, ainda que o presidente tenha se apoiado no discurso da luta do bem contra o mal. Do ponto de vista da segurança, isso se cristalizou na formação da Organização do Tratado da Aliança do Atlântico Norte (OTAN) em 1949. Na extremidade oriental da Eurásia, foram estabelecidos acordos de segurança bilaterais, após a Revolução Comunista na China em 1949 e a Guerra na Península da Coreia iniciada em 1950. Brzezinski e Kissinger formularam visões geoestratégicas e guias de ação para os EUA nesse sentido, mantendo o foco geopolítico na Eurásia.

Brzezinski (1986), em Game Plan, apontou a Eurásia como o continente basilar na confrontação entre EUA e URSS. Ainda, atribuiu uma razão geográfica para o conflito e seus possíveis desdobramentos, ao afirmar que se tratava de uma colisão entre uma potência marítima transoceânica, que passou a identificar 
as bordas da Eurásia como seu perímetro de segurança e área de atuação, e um poder terrestre transcontinental, que tinha como imperativo geoestratégico a expansão para essa mesma área da Eurásia em busca de uma saída para os “mares quentes". A primeira tentava conter a segunda e confiná-la no interior da Eurásia, enquanto a segunda buscava expulsar a primeira da Eurásia e isolá-la no continente americano.

Para o autor, tal rivalidade pela Eurásia se desenvolveu em três frentes estratégicas, originadas em diferentes momentos, a saber: na extremidade ocidental da Eurásia, entre 1947-1949, com a tentativa de ascensão comunista na Grécia e na Turquia e a Crise de Berlim; na extremidade oriental da Eurásia, originada com a Revolução Comunista na China em 1949 e a Guerra da Coreia em 1950; a frente do Sudoeste Asiático, envolvendo o Oriente Médio, impulsionada em 1979 pela invasão soviética ao Afeganistão e pela Revolução Islâmica no Irã. O controle dessa última área seria crucial para o poder de barganha e influência dos EUA sobre as demais em razão de sua importância para o abastecimento de petróleo, não só dos EUA, mas para os aliados. Seu controle possibilita aos EUA a capacidade de atuar como uma espécie de garantidor do acesso aos bens energéticos - ou do funcionamento do "mercado", além de negar acesso a rivais revelados ou potenciais. Isso se cristalizou na chamada Doutrina Carter formulada por Brzezinski como seu assessor de segurança, sintetizada pelo presidente no seu discurso ao congresso em 1980 (KLARE, 2005).

Embora não desenvolva suas reflexões fundamentadas em fatores geográficos, mas em termos de balança de poder, Kissinger (1994), em Diplomacia, destaca a importância da estratégia estadunidense para a Eurásia como um elemento basilar para sua supremacia e rivalidade diante da URSS. Na referida obra, destaca que, a partir da percepção de temor mútuo entre URSS e China, formulou e trabalhou junto ao presidente Nixon na diplomacia triangular como estratégia geopolítica dos EUA frente à URSS e à China, aproximando os EUA da última.

Ambos, Brzezinski e Kissinger, encaram a supremacia hemisférica dos EUA como um fator permanente na sua geoestratégia no âmbito da Guerra Fria. Portanto, a América Latina é vista como uma área periférica, mas de intervenção contínua dos EUA. Vale colocar em relevo as formulações de James Burnham (1947), na qual a visão geopolítica de contenção é ampliada para regiões mais periféricas onde a penetração do comunismo se caracterizaria pela criação de redes de subversão. Nessas áreas e países, os EUA deveriam atuar apoiando a contenção da guerra revolucionária e insurrecional. 


\section{Brzezinski e Kissinger: a geoestratégia dos EUA no pós Guerra Fria}

No debate geoestratégico dos EUA no século XXI, Brzezinski e Kissinger seguem apontando a centralidade das relações Leste-Oeste em suas análises geoestratégicas, ou seja, entre os países do hemisfério norte. Mais especificamente, o equilíbrio de poder na Eurásia a ser promovido pelos EUA segue como decisivo. Mas, dependendo da conjuntura, atribuem foco e intensidade de atuação estratégica estadunidense diferenciada para as áreas da Eurásia, conjugando tática e estratégia.

No livro Strategic Vision, assim como no artigo Balancing the East, Upgrading the West - U.S. Grand Strategy in an Age of Upheaval, Brzezinski (2012a; 2012b) aponta desafios e caminhos para que os EUA mantenham sua posição de primazia. Quanto às recomendações, o autor começa deixando claro que é fundamental promover um equilíbrio geopolítico novo e estável na Eurásia, “de longe, o continente mais importante do mundo" (BRZEZINSKI, 2012a, p.130), geopoliticamente axial por questões materiais, citando Mackinder. Na sua visão, os EUA desperdiçaram a oportunidade de avançar no vácuo de poder pós Guerra Fria, quando emergiu como único superpoder global. Após os ataques de 11 de setembro de 2001, a "guerra ao terror" de George W. Bush teria transformado os EUA num "Estado cruzadista", deixando-o despreparado para encarar os novos desafios geopolíticos do século XXI e carente de uma visão estratégica de longo prazo, o que levou a uma deterioração do seu poder relativo. Ao mesmo tempo, afirma que o presidente Obama não teria promovido as mudanças necessárias para estabelecer uma visão de longo prazo (BRZEZINSKI, 2012a, p. 122). A Europa está menos unida e mais fraca (se tornou uma extensão do Ocidente, sem visão estratégica e dependente militarmente dos EUA), enquanto Turquia e Rússia ficaram à margem da comunidade ocidental, e no Oriente a China tem crescido em termos econômicos, políticos e militares, criando rivalidades reais e potenciais. Assim, para Brzezinski, atualmente a Eurásia apresenta volatilidades que a colocam como a arena central da geopolítica global, onde: (1) as ameaças imediatas provém do leste do Canal de Suez, do oeste da província chinesa de Xinjiang, e da fronteira sul pós soviética (do Cáucaso e da Ásia Central); (2) o desafio de longo prazo é a contínua mudança do centro de gravidade (distribuição de poder global) do Ocidente para o Oriente, da Europa para a Ásia, e possivelmente dos EUA para a China. Essa impõe a necessidade de uma visão geoestratégica de longo prazo visando a promoção de um equilíbrio de poder transcontinental na Eurásia (BRZEZINSKI, 2012a, p.123). 
Para isso, Brzezinski propõe que os EUA devem atuar como o promotor e garantidor de um renovado "Ocidente Ampliado" (Larger West), envolvendo a Turquia e a Rússia, de forma gradual, por meio de um processo de democratização e eventualmente aderindo às normas do "Ocidente". Esse objetivo de longo prazo poderia ser alcançado no segundo quarto do século XXI. A Turquia se destacaria por sua influência histórica na área do antigo Império Otomano, por atuar como uma ponte de acesso da Europa ao Mar Cáspio e à Ásia Central (via aliança com Geórgia e Azerbaijão), que são áreas disputadas com a Rússia, e por ter sido em parte já incorporada ao Ocidente através da OTAN. A relevância da Rússia se deve à sua posição geográfica central e transcontinental na Eurásia, e por ter em sua orientação geoestratégica a retomada do status de antigo império, que busca influência sobre a Ásia Central e sobre parte da Europa dividida. Assim, nessa tarefa, a liderança dos EUA na OTAN seria imprescindível, assim como trabalhar por uma Europa unida, fomentando a cooperação entre seus atores chave.

Outro tabuleiro seria o "Oriente Complexo", na região Ásia-Pacífico, onde os EUA deveriam atuar como um promotor do equilíbrio regional de "um novo oriente estável e cooperativo". Para ele, por seu peso econômico e demográfico frente a uma Europa declinante, essa região é crucial para a estabilidade global. No entanto, apresenta enorme potencial de eclodir um conflito local que pode arrastar os EUA e levar a uma guerra maior. Isso se deve às disputas pelo posto de maior potência regional, combinado com ressentimentos, desconfianças, contenciosos e conflitos históricos, envolvendo também aliados estratégicos dos EUA (BRZEZINSKI, 2012a, p.157-158). Para Brzezinski, as ambições chinesas se tornam cada vez mais claras, assentadas em assertividade nacionalista, modernização nacional e paciência histórica, que despertam medo e rivalidades históricas com Japão e Índia, por exemplo. Assim, os EUA deveriam ajudar os países a evitar uma batalha pelo domínio da região, mediando conflitos e promovendo o equilíbrio entre rivais. Mas alerta que os EUA não podem mais impor um equilíbrio de poder à região (BRZEZINSKI, 2012a, p.131, 161). Mas, para ele, embora seja apontada frequentemente como a sucessora dos EUA, a China não estaria preparada, disposta ou interessada em assumir o papel global dos EUA. Pelo contrário, busca maior influência, de forma paciente, cautelosa e não conflitante, entendendo que um rápido declínio dos EUA levaria a uma crise global que não a interessaria, já que o país tira proveito da ordem promovida pelos EUA sem incorrer nos seus custos. Até porque sua geografia possibilita um 
possível cerco por parte dos rivais vizinhos (BRZEZINSKI, 2012a, p.79-89, 119).

Na visão de Brzezinski (2012a), os EUA deveriam se aproximar da China, e não só diminuir as possibilidades de um conflito EUA-China, mas também trabalhar para que não haja erros de cálculo e conflitos entre Japão e China, China e Índia e China e Rússia. Devem buscar estabelecer um triângulo estratégico de cooperação entre EUA-Japão-China, envolvendo uma duradoura reconciliação entre China e Japão, e atuar dentro do princípio de que os EUA devem manter obrigações com Japão e Coreia do Sul, mas, ao mesmo tempo, não permitindo ser arrastado para uma guerra entre potências asiáticas. Aponta que, nesse quadro conflitivo potencial, sua estabilidade depende em parte de como os EUA vão lidar com dois triângulos regionais sobrepostos centrados na China, onde ele pode ser um ator chave para alterar equilíbrios e resultados (BRZEZINSKI, 2012a, p.162). Primeiro, o triângulo China-Índia-Paquistão, que envolve a primazia na Ásia entre os dois primeiros, numa relação inerentemente competitiva e antagônica, tendo o terceiro como ponto regional de contenção. Nesse caso, o papel dos EUA deve ser cauteloso e prudente, especialmente na aliança com a Índia, evitando envolvimento militar, para não despertar ou legitimar uma hostilidade nacionalista chinesa, que inclusive interessaria à Rússia. A conveniência de tal postura já não ficaria clara no segundo triângulo, China-Japão-Coreia do Sul, no Sudeste da Ásia, por envolver a questão da primazia da China frente à posição dos EUA no Pacífico. De qualquer forma, um Japão fortalecido e ativo traria uma contribuição importante para a estabilidade global.

Por fim, Brzezinski (2012a, p.181) afirma que, se os EUA forem bem-sucedidos no Ocidente, formando uma ampla zona de cooperação democrática e estável da América do Norte à Europa, estendendo-se através da Eurásia (eventualmente envolvendo Rússia e Turquia) na direção do Japão e da Coreia do Sul, elevaria o apelo dos princípios centrais do Ocidente frente a outras culturas, encorajando a emergência de uma cultura política democrática universal.

Kissinger (2014, p. 374), em Word Order, aponta que os EUA precisam de uma estratégia e de uma diplomacia à altura para manter sua supremacia diante da complexidade da(s) ordem(s) internacional(is) atual(is). Ao destacar a importância geopolítica e histórica da parceria atlântica para os EUA, Kissinger assinala que é fundamental sua renovação e continuidade, assim como apoiar a União Europeia e evitar que ela desande para um vácuo político, pois: 
Separados da Europa no plano da política, da economia e da defesa, os Estados Unidos, em termos geopolíticos, se tornariam uma ilha ao largo da Eurásia, e a própria Europa poderia ser um prolongamento das extensões da Ásia e do Oriente Médio (KISSINGER, 2014, p.99-100).

Kissinger aponta que a ordem internacional na Ásia é historicamente caracterizada pela participação de potências externas, atualmente marcada por uma "variedade de grupos multilaterais e mecanismos bilaterais" (KISSINGER, 2014, p. 210-211), alguns puramente regionais e alguns com participação inclusive dos EUA ou da Rússia. Na opinião do autor, a região apresenta uma complexidade geoestratégica por conta de suas rivalidades regionais e apresenta duas balanças de poder: uma no Sul e outra no Leste. Embora tenha procurado não tratar da balança do Sul após sua retirada do Afeganistão, para ele, os EUA não poderão deixar de atuar na mesma, pois deixariam um vácuo de poder para expansionismos e rivalidades que levaria à confrontação (KISSINGER, 2014, p.212-213). Já no Leste da Ásia, aponta que os EUA não são tanto um promotor quanto parte integral do equilíbrio. Há vários equilíbrios nessa área, inclusive um entre EUA, Japão e China. Para ele, a atuação dos EUA exigirá moderação, força e legitimidade, combinando equilíbrio de poder com o conceito de parceria, para evitar uma confrontação militar ou uma hegemonia chinesa.

Sobre as relações EUA-China, na visão de Kissinger, mesmo que os EUA declinem, os lideres estatais chineses sabem que preservarão muito do seu poder. Para ele, nenhum país sozinho tem a capacidade de exercer o papel de liderança dos EUA. Mas percebe que a China representa um desafio estrutural na distribuição de poder global. Por isso, é preciso evitar uma tragédia, como as guerras hegemônicas que ocorreram na Europa no início do século XX. A relação entre EUA e China deve ser regida pela busca de equilíbrio baseado tanto no poder quanto na legitimidade. Os EUA não podem deixar de ter um olho na balança de poder ao buscar normas para estabelecer legitimidade e cooperação, e vice-versa (KISSINGER, 2014).

Assim, Brzezinski e Kissinger atribuem importância à atuação permanente dos EUA na Eurásia e na OTAN, embora o primeiro se mostre um legítimo herdeiro da geopolítica clássica, enquanto o segundo baseie mais sua análise em uma política de equilíbrio de poder global. A atuação no Oriente Médio também aparece como importante para ambos: no sentido de garantir o abastecimento dos aliados e negar acesso a rivais potenciais ou revelados, auferindo maior poder de barganha, não importando os custos econômicos de tais ações, que são superados pelos ganhos 
estratégicos. Se a China se aproveita da presença militar e estabilidade patrocinada pelos EUA na região, a partir da visão de Michael Klare (2008), podemos interpretar que seu controle, especialmente em momentos de crise e conflitos, é fundamental politicamente. É importante ressaltar que, nas análises geoestratégicas tanto de Brzezinski quanto de Kissinger, as preocupações centrais (prioridades) são discutir e delinear objetivos geoestratégicos (de segurança) que não devem ser limitados por debates economicistas e orçamentários, o que seria inadequado, já que os EUA é o país emissor da moeda internacional sem lastro. Ainda que Brzezinski (2012a) vislumbre que o endividamento dos EUA diante de um crescente credor que é um potencial contestador de sua posição de supremacia, a China, poderia levar a uma vulnerabilidade e a um questionamento da hegemonia estadunidense e de sua moeda internacional no longo prazo.

Sobre o continente americano, e a América Latina, ambos autores apontam como imprescindível a hegemonia estadunidense, e deve ter atenção permanente no seu cálculo estratégico, embora o foco principal seja a Eurásia. Assim, a projeção de potências externas deve obter uma atenção e ações cuidadosas por parte dos EUA, principalmente para não despertar hostilidades por parte dos governos (com apelo em suas sociedades) dos demais países do continente. Sobre o México, Brzezinski (2012a) afirma que os EUA deveriam cooperar pelo desenvolvimento através do NAFTA e pela segurança através do apoio ao combate aos cartéis de drogas. Mas alerta que um EUA declinante levaria a um nacionalismo protecionista e anti-imigração estadunidense e a um revanchismo e a reivindicações de territórios perdidos por parte do México. Nesse contexto, a China desempenharia um papel mais relevante no hemisfério ocidental.

Vale destacar que Brzezinski e Kissinger divergem em suas visões sobre as relações EUA-China e EUA-Rússia. Kissinger (2014) destaca as relações triangulares com China e Japão e com Rússia e China. Ele critica a demonização da Rússia. Afirma que essa deve ser abordada como uma grande potência na estratégia e nas negociações diplomáticas pelos EUA, adaptando-se (e não dando um "reset”) às circunstâncias atuais. Assim, os EUA não podem chegar e impor um "plano pronto", tampouco encarar a Rússia como um membro potencial e natural da OTAN, que aderiria automaticamente às regras do chamado Ocidente (KISSINGER, 2016b). É preciso entender a história e a natureza da insegurança russa, assim como sua importância geográfica, órbita de influência e natureza expansionista. Só assim é possível estabelecer relações que busquem reconhecer suas características especiais, mas também compreender as necessidades dos EUA. Para Kissinger, “O 
objetivo deve ser encontrar uma diplomacia para integrar a Rússia a uma ordem mundial que deixe margem para cooperação “ (KISSINGER, 2016a, tradução nossa). ${ }^{3}$

Kissinger argumenta sobre a possibilidade de uma geopolítica triangular EUA-Rússia-China, com os EUA se aproximando do vértice mais fraco (Rússia) para se contrapor ao mais forte (China), nos moldes da estratégia praticada por Nixon-Kissinger frente à URSS. Atualmente, o desafio estrutural para os EUA está na China. Por isso, "Na emergente ordem multipolar, a Rússia deve ser vista como um elemento essencial de qualquer novo equilíbrio global, não preliminarmente como uma ameaça aos Estados Unidos" (KISSINGER, 2016c, tradução nossa). ${ }^{4}$ Deve-se ter em conta que Kissinger não acredita que China e Rússia possam estabelecer uma reaproximação duradoura devido às suas naturezas. Na sua visão, se a Rússia mostra claramente querer isso, é em parte porque os EUA não lhe deixaram escolha. Finalmente, para Kissinger

... o desafio da China é um problema muito mais sutil que aquele colocado pela União Soviética. O problema soviético era em grande parte estratégico. Esta é uma questão cultural: podem duas civilizações que não pensam de forma igual, pelo menos até agora, chegar a uma fórmula de coexistência que produza ordem mundial? (KISSINGER, 2015, tradução nossa). ${ }^{5}$

Já Brzezinski, a partir da crise de 2008, passou a advogar a formação de um G2 (group of two) informal entre China e EUA, baseado na interdependência e interesse comum entre ambos, cooperando em uma espécie de hegemonia compartilhada, na qual os Estados Unidos reconhecessem a importância econômica chinesa - e da prática de um keynesiamismo orientado a impulsionar a economia estadunidense - enquanto os EUA mantêm seu papel de supremacia político-militar e tecnológica (BRZEZINSKI, 2009). Em sua obra, as possibilidades de uma parceria e cooperação entre EUA e Rússia aparecem sempre como remotas, devido aos antagonismos geográficos e consequentes divergências geopolíticas, explicitados, por exemplo, após a crise da Ucrânia (BRZEZINSKI, 1986; 2012).

3 "The goal should be to find a diplomacy to integrate Russia into a world order which leaves scope for cooperation".

4 "In the emerging multipolar order, Russia should be perceived as an essential element of any new global equilibrium, not primarily as a threat to the United States".

5 "... the challenge of China is a much subtler problem than that of the Soviet Union. The Soviet problem was largely strategic. This is a cultural issue: Can two civilizations that do not, at least as yet, think alike come to a coexistence formula that produces world order?" 


\section{A geoestratégia dos EUA: sua continuidade pós Guerra Fria}

Esta seção se dedica à geoestratégia estadunidense pós Guerra Fria revelada em documentos estratégicos de Estado selecionados, com destaque à relação com a Eurásia e a América Latina, a partir de objetivos, interesses e ameaças apresentados.

Com o fim da Guerra Fria, da dissolução da URSS e do bloco socialista, os EUA deixavam de possuir uma ameaça clara a combater que legitimasse seus altos gastos militares e presença militar global. Assim, seria preciso identificar novas ameaças que fossem palatáveis dentro e fora das suas fronteiras. Olhando para a OTAN, a questão se torna ainda mais complexa, visto que foi criada sob a liderança dos EUA no âmbito da Doutrina Truman com a missão de conter o avanço socialista-soviético na Europa. Ao mesmo tempo, representa um instrumento para a presença e controle militar estadunidense na região. Assim, do ângulo da geoestratégia dos EUA, era preciso dar um novo sentido à organização.

Nesse momento, os EUA começaram a promover a retórica de que o mundo pós Guerra Fria seria pacífico, livre de disputas e conflitos interestatais globais, apenas com algumas conturbações regionais. Ao mesmo tempo, elegeram como novas ameaças à paz e à estabilidade global as de caráter não estatais, como o narcotráfico, catástrofes ambientais, inimigos do meio ambiente, fluxos migratórios conturbadores, o terrorismo de grupos islâmicos radicados e espalhados em diferentes países - que posteriormente configurariam o terrorismo global —, mas também Estados (ou líderes) violadores de direitos humanos e da democracia, os Estados “irresponsáveis" que viessem a apoiar grupos terroristas, ou Estados falidos cuja fraqueza favorecesse o surgimento e manutenção de tais grupos em seus territórios. Especificamente na América Latina, o discurso sobre o combate ao narcoterrorismo ganhou maior ênfase por conta da adesão e legitimidade entre os governos da região dos anos de 1990, na sua maioria alinhados à Washington.

Confeccionado no governo republicano de George H. W. Bush (1989-1993), o documento National Military Strategy of the United States - NMS, de 1991 (USA,1991), sublinhou a importância de tais ameaças. E, assim, a agenda de segurança baseada em novas ameaças que os EUA promoveriam através de organizações multilaterais regionais, como a OTAN e OEA, e na ONU, no âmbito global. Com otimismo, anuncia o surgimento de uma nova era a partir da derrocada do socialismo e do sucesso na Guerra do Golfo, através de uma ação militar extremamente bem-sucedida autorizada pelo Conselho de Segurança da ONU, 
orquestrada pelos EUA e mostrando sua superioridade militar e capacidade de liderança em uma ordem unipolar.

No entanto, uma avaliação mais acurada do NMS-1991 revela que a disputa interestatal segue tendo papel central nos objetivos militares estadunidenses, mais especificamente no sentido de minar a possibilidade do surgimento de potências regionais e desafiantes globais em um cenário global incerto (de transição) pós Guerra Fria ${ }^{6}$. O objetivo de preservar a confiança na capacidade dos EUA de prevenir qualquer perigo real de ameaçá-lo ou competir militarmente aparece como decisivo. Com grande foco na promoção do equilíbrio regional e em disputas interestatais, revela-se uma preocupação em manter a Europa Ocidental unida, mas, em termos de forças militares e identidade de segurança, cada vez mais atrelada à OTAN, sob a tutela dos EUA - e não formando uma força própria independente. Especificamente sobre a Alemanha, fica claro o objetivo de mantê-la como um protetorado militar dos EUA, combinado a um protagonismo econômico e político regional. A Europa, sob a órbita da OTAN, seria importante para aproveitar as oportunidades do vácuo de poder deixado no Leste Europeu pelo fim da URSS.

Quanto ao Japão e à Ásia-Pacifico, o NMS-1991 aponta como objetivo reforçar os laços militares bilaterais, reconhecendo o papel de protagonista do país do ponto de vista econômico, mas, ao mesmo tempo, impedindo sua remilitarização - nesse momento, a China ainda não mostrava a pujança dos anos 2000.

Sobre a Rússia, herdeira do arsenal nuclear soviético, o documento revela a crença na persistência de rivalidades e aponta a necessidade de evitar que ela volte a ser o que era quarenta anos antes, com sua robustez militar competitiva. Ou seja, seria preciso conter sua remilitarização, ao mesmo tempo buscando promover sua democracia.

Ainda, o NMS-1991 reafirma a preocupação permanente com o hemisfério ocidental na direção de uma política de segurança em que as forças militares na América Latina tenham sua capacidade restringida à autodefesa, combater o narcotráfico, atuar em assistência a catástrofes e manter a paz internacional (consistente com os princípios e missões da OEA e da ONU), onde temas como direitos humanos e florescimento e manutenção de democracias são repetidos por

6 "No Golfo, vimos os Estados Unidos desempenhando o papel sonhado por seus fundadores, sendo a nação líder do mundo orquestrando e sancionando a ação coletiva contra a agressão. Mas ainda nos mantemos em um período de transição". No original, "In the gulf, we saw the United States playing the role dreamed of by its founders, with the world's leading nation orchestrating and sanctioning collective action against aggression. But we still remain in a period of transition” (USA, 1991, p. 5, tradução nossa). 
diversas vezes. A agenda hemisférica dos EUA busca proliferar a noção de que as ameaças à segurança dos países latino-americanos se originariam de inimigos internos ou atores transnacionais difusos.

A importância da promoção de uma agenda de livre-comércio e, de forma mais ampla, de liberalização econômica, é amplamente citada no documento, e persiste nos documentos dos governos posteriores aqui abordados. Nos países periféricos, a combinação de uma agenda de liberalização econômica, que levaria à sua desindustrialização e menor capacidade de gerar tecnologias de ponta, com uma agenda de segurança voltada a inimigos internos moldando suas forças armadas, levaria inevitavelmente à dependência e inferioridade no campo bélico em relação aos EUA.

Do ponto de vista das visões de Brzezinski e Kissinger e da herança geopolítica clássica anglo-saxã, é importante notar que os documentos abordados do governo republicano de Bush revelam-se congruentes ao destacar o foco nas disputas interestatais e na Eurásia, a importância das relações com a Europa sob a tutela da OTAN e dos EUA, a desconfiança em relação a um possível ressurgimento da Rússia como rival geopolítico histórico, o controle do Oriente Médio e do Sudeste da Ásia, tutelando o Japão, e a supremacia hemisférica na América. Toda retórica sobre novas ameaças aponta para a necessidade de um discurso ético e legitimador de uma política mais ampla de manutenção da supremacia, de altos gastos e presença militar global.

Na verdade, a década de 1990 não foi pacífica, mas um período caracterizado por várias intervenções militares, por exemplo, na antiga Iugoslávia e na Somália (além da intervenção no Golfo já citada), muitas sob o manto de causas humanitárias, especialmente durante o governo democrata de Bill Clinton (1993-2001).

Os documentos A National Security Strategy of Engagement and Enlargement de 1994 e de 1996 confirmam a mudança retórica quanto às ameaças a serem combatidas pelos EUA com o fim da Guerra Fria, mas tornando-as mais diversas, apontando: os conflitos étnicos e os rogue states que colocam ameaças à estabilidade regional em várias partes do globo, a proliferação de armas nucleares como um desafio maior, a degradação ambiental e o crescimento demográfico ameaçando a estabilidade política de vários países e regiões, além de sublinhar a importância do combate ao narcotráfico, da promoção da democracia e dos direitos humanos. Embora tenha como pano de fundo um discurso multilateralista, que prima pelo papel dos organismos internacionais e pela "governança global”, os documentos revelam como objetivos centrais dos EUA, que se reforçam mutuamente: 
a confiança nas suas forças militares, sua revitalização econômica e a promoção da democracia. Observa as oportunidades sem precedentes apresentadas aos EUA pela assimetria de poder no sistema internacional pós Guerra Fria. No entanto, aponta que "Mesmo com o fim da Guerra Fria, nossa nação precisa manter forças militares suficientes para deter diversas ameaças e, quando necessário, lutar e vencer nossos adversários" (USA, 1994, p.ii, tradução nossa). ${ }^{7}$ Mais adiante, o documento aponta que a Rússia possui um futuro incerto e que a China mantém um regime repressivo, mesmo assumindo um papel mais importante em temas econômicos e políticos internacionais. Isso reforçaria o imperativo estratégico de atuar na Eurásia, condizente com as visões de Brzezinski e Kissinger herdadas da geopolítica clássica. Ainda, nesse mesmo sentido, os documentos tratam da atuação em diferentes áreas da Eurásia, na OTAN e no hemisfério ocidental, com o objetivo de manter a supremacia estadunidense no pós Guerra Fria.

Com o objetivo de promover a paz e a estabilidade em diferentes partes do planeta, os documentos observam a importância da parceria transatlântica no âmbito da OTAN, sob a liderança dos EUA, assim como seu papel na promoção de tratados de livre-comércio. Destaca que Clinton convocou uma reunião de cúpula da OTAN, em janeiro de 1994, que aprovou a Partnership For Peace, fundamental para reforçar os laços transatlânticos e promover a estabilidade da Europa. Ambos os documentos citados do governo Clinton afirmam que a estabilidade europeia é vital para a segurança dos EUA. Esse deve ter como elemento mais importante na sua estratégia na Europa a promoção da segurança através de cooperação e fortalecimento militares, ajudando a confirmar o papel central da OTAN na Europa, pois "A Guerra Fria acabou, mas a guerra em sim não acabou" (USA, 1994, p. 21, tradução nossa). ${ }^{8}$ Assinala a oportunidade sem precedentes de contribuir em favor de uma Europa livre e unida, mas que seja cooperativa com os EUA. O objetivo de levar a agenda de "novas ameaças" à OTAN já estava claro nas intervenções dos anos de 1990: "Actualmente, a OTAN desempenha um papel crucial, ajudando a gerir conflitos étnicos e nacionais na Europa. Com a liderança dos EUA, a OTAN proveu a força por detrás dos esforços para a consecução de um acordo pacífico na antiga Jugoslávia” (USA, 1996, p. 32, tradução nossa). ${ }^{9}$ Nesse sentido, afirma

\footnotetext{
7 "Even with the Cold War over, our nation must maintain military forces that are sufficient to deter diverse threats and, when necessary, to fight and win against our adversaries”.

8 "The Cold War is over, but war itself is not over".

9 "Today, NATO plays a crucial role helping to manage ethnic and national conflict in Europe. With U.S. leadership, NATO has provided the muscle behind efforts to bring about a peaceful settlement in the former Yugoslavia".
} 
o objetivo de ampliar a OTAN e levar a democracia em direção ao leste, para a área antes influenciada pela URSS.

Ao destacar que o Leste da Ásia é uma região de crescente importância para a prosperidade e segurança dos EUA, o documento aponta que Clinton busca uma estratégia integradora de uma "nova comunidade do Pacífico”, "que liga os requisitos de segurança às realidades econômicas e nossa preocupação com a democracia e os direitos humanos” (USA, 1994, p. 21, tradução nossa). ${ }^{10}$ A pedra angular dessa política seria o aprofundamento de laços bilaterais com aliados (como Japão, Coreia do Sul, Austrália, Tailândia e Filipinas), combinado com a continuidade da presença militar estadunidense.

Quanto à segurança hemisférica, a parte do documento de 1994 chamada Integrated Regional Approaches: the Western Hemisphere promove o foco nas novas ameaças e na democracia, assim como a Cúpula das Américas e as Conferências de Ministros da Defesa seriam os instrumentos de difusão dessa agenda. Ainda, comemora a criação do NAFTA em 1994.

Voltando ao tema da OTAN, sua “nova doutrina” pós Guerra Fria foi anunciada durante a comemoração dos seus 50 anos. Um dos itens do capítulo quinto do documento NATO 2020: Assured Security; Dynamic Engagement revelou o novo conceito estratégico da OTAN:

Desdobrar e sustentar capacidades expedicionárias para operações militares além da área abrangida pelo tratado quando requerido para impedir um ataque na área abrangida pelo Tratado ou para proteger os direitos e outros interesses vitais dos membros da Aliança. (NATO, 2020, tradução nossa) ${ }^{11}$

Assim, foram flexibilizadas tanto a área geográfica de atuação quanto as ameaças a serem combatidas, que passam a ser subjetivas e imprecisas, de acordo com o que seus membros identificarem ou interpretarem. É nesse quadro que observamos a expansão da OTAN para o leste (assim como a da União Europeia), sob o comando dos EUA, incluindo antigos membros do Pacto de Varsóvia, numa área observada pela Rússia como de interesse estratégico. Tal manobra geopolítica, mais uma vez, segue os preceitos da geopolítica clássica, presentes nas visões de Brzezinski e Kissinger ao abordarem a rivalidade geopolítica com a Rússia e a importância da Eurásia.

10 “...which links security requirements with economic realities and our concern for democracy and human rights”.

11 "Deploy and sustain expeditionary capabilities for military operations beyond the treaty area when required to prevent an attack on the treaty area or to protect the legal rights and other vital interests of Alliance members". 
A preocupação com a dependência energética externa dos EUA aparece no documento de 1998, A National Security Strategy for a New Century, destacada na seção "Providing for energy security":

Os Estados Unidos dependem do petróleo para cerca de $40 \%$ de suas necessidades de energia primária e cerca de metade de nossas necessidades de petróleo são atendidas com importações. Embora importemos menos de $10 \%$ das exportações do Golfo Pérsico, nossos aliados na Europa e no Japão representam cerca de $85 \%$ dessas exportações, ressaltando assim a importância estratégica contínua da região. (USA, 1998, p.32, tradução nossa) ${ }^{12}$

Tal quadro reforça a importância da Eurásia e do Oriente Médio. Na verdade, reflete uma dinâmica histórica de crescente dependência de importações de petróleo, assim como a preocupação com o papel de "guardião” do abastecimento dos aliados como um mecanismo de influência política, realçada na seção anterior. Por isso, tanto Brzezinski quanto Kissinger apontam a importância de os EUA permanecerem e participarem ativamente da política no Oriente Médio. Klare (2005, p. 13) destaca que, em 1973, as importações de petróleo dos EUA ultrapassaram a marca de $30 \%$ do consumo interno; em 1976, alcançaram $40 \%$; atingindo $45 \%$ em 1977. Nesse âmbito, com a invasão soviética ao Afeganistão e a revolução iraniana em 1979, foi lançada a Doutrina Carter, e o Comando Central dos EUA foi criado em 1983 para atuar no Oriente Médio. Em 1997, as importações chegaram a 49\% do abastecimento interno e, em 1998, ultrapassam a barreira dos 50\%, um marco, digamos, psicológico, perto da chegada do século XXI. Na interpretação de Klare (2008), desde a Segunda Guerra Mundial, quando os EUA atuaram como principal abastecedor petroleiro das potências aliadas, a Doutrina Carter seguiu e seguirá guiando a estratégia estadunidense, na qual a segurança energética é vista como um tema de segurança nacional, e não como um tema econômico — reforçando que suas máquinas militares são movidas predominantemente a petróleo.

O republicano George W. Bush (2001-2009) chega ao poder comprometido com as prioridades estabelecidas pelo grupo neoconservador do think tank "Project for the New America Century" (PNAC), que passaram a guiar a geoestratégia estadunidense: aumentar gastos com defesa, promover a "liberdade política" em todo o mundo e preservar e estender uma ordem internacional amigável.

12 "The United States depends on oil for about 40 percent of its primary energy needs and roughly half of our oil needs are met with imports. Although we import less than 10\% of Persian Gulf exports, our allies in Europe and Japan account for about $85 \%$ of these exports, thus underscoring the continued strategic importance of the region". 
Sobretudo, ganha destaque o objetivo de aumentar os fluxos de petróleo e gás do exterior, diante do problema de segurança energética (e da redução de estoques) dos EUA, cujas importações eram responsáveis por mais da metade do consumo interno e mais de $30 \%$ do déficit comercial. Tais prioridades podem ser buscadas de forma coadunada e sinérgica, por isso mostram organicidade e, em termos políticos, ganharam maior legitimidade retórica e viabilidade de perseguição após os ataques terroristas de 11 de setembro de 2001.

Em 2002, o documento National Security Strategy explicitou a doutrina de "ataques preventivos", que deu maior flexibilidade para a atuação militar dos EUA, desde que identificassem unilateralmente uma ameaça potencial atrelada à atuação de grupos terroristas, em qualquer parte ou território nacional do globo. O discurso unilateralista neoconservador, que via o multilateralismo como uma demonstração de fraqueza, ganha força como um discurso ético de luta contra o mal, legitimador de uma intervenção global: "Milhares de terroristas treinados permanecem à solta com células na América do Norte, América do Sul, Europa, África, Oriente Médio e toda a Ásia." (USA, 2002, p. 5, tradução nossa). ${ }^{13}$

A importância da OTAN como uma espécie de força militar global da ONU, sob a tutela e incorporando a agenda de segurança dos EUA, é reforçada no governo Bush, como afirma o documento da estratégia nacional de 2006 (USA, 2006, p. 35-38). Ao mesmo tempo, deixa pistas de que intervenções militares, com ou sem o consentimento da ONU, em áreas ricas em petróleo ou rotas estratégicas podem ser necessárias.

A dependência mundial desses poucos fornecedores não é responsável nem sustentável a longo prazo. A chave para garantir nossa segurança energética é diversificar as regiões de onde vêm os recursos energéticos e os tipos de recursos energéticos de que dependemos. A Administração trabalhará com países ricos em recursos para aumentar sua abertura, transparência e estado de direito. Isso promoverá uma governança democrática efetiva e atrairá o investimento essencial para o desenvolvimento de seus recursos e a expansão da gama de fornecedores de energia. (USA, 2006, p.37, tradução nossa) ${ }^{14}$

13 "Thousands of trained terrorists remain at large with cells in North America, South America, Europe, Africa, the Middle East, and across Asia”.

14 "The world's dependence on these few suppliers is neither responsible nor sustainable over the long term. The key to ensuring our energy security is diversity in the regions from which energy resources come and in the types of energy resources on which we rely. The Administration will work with resource-rich countries to increase their openness, transparency, and rule of law. This will promote effective democratic governance and attract the investment essential to developing their resources and expanding the range of energy suppliers". 
Assim como nas recomendações de Brzezinski e Kissinger, os documentos estratégicos do governo Bush destacam a importância da atuação política e militar dos EUA na Eurásia, como continente basilar, mas com maior ênfase no Oriente Médio, devido a questões conjunturais - como a necessidade de controlar o acesso a fontes energéticas e combater o terrorismo. É interessante ressaltar que, nesse período, já se destacam mudanças importantes. Uma delas, a clara ascensão econômica da China e da Índia, com elevadas taxas de crescimento do PIB, em média $8 \%$ e $6 \%$ ao ano, respectivamente (enquanto, nos anos de 1990, foram de $6 \%$ e $4 \%$ ao ano). Ainda, a retomada de uma política externa mais assertiva da Rússia, especialmente no seu entorno geográfico da antiga URSS. Questões que tiveram uma dose de "déficit de atenção" nos documentos estratégicos analisados, e que apoiam a crítica de Brzezinski (2012a) anteriormente mencionada, de que os EUA teriam se tornado um "Estado cruzadista" sem visão estratégica de longo prazo diante dos grandes desafios do século XXI.

Quanto à preocupação com a China, apontava para seu regime político autocrático, sua contínua expansão militar sem transparência e práticas econômicas protecionistas, incluindo a busca por acesso garantido a recursos energéticos por meio de acordos políticos e utilizando investimentos/financiamentos como instrumentos, e até mesmo apoiando países abundantes em recursos naturais com regimes políticos não democráticos (USA, 2006). No entanto, não há qualquer menção sobre a distribuição de poder global ou um desafio à superioridade estadunidense.

Quanto à Rússia, a continuidade da expansão para o leste da OTAN e interações militares (como venda de armamentos e treinamento), englobando Estados da antiga URSS e chegando às fronteiras da Rússia, e a proposta de instalação de um escudo antimísseis no Leste Europeu, tendo como contrapartida uma postura assertiva russa, marcaram a reativação das tensões e uma postura não cooperativa nas relações bilaterais por parte dos EUA no governo George W. Bush, e desembocaram no conflito entre Rússia e Geórgia.

Devido à herança recebida do governo anterior, especialmente seu envolvimento e foco no Oriente Médio, a política do governo democrata de Barack Obama para a Ásia se caracterizou inicialmente por uma postura reativa. No entanto, em 2010 é possível identificar um redirecionamento do foco da política externa e de segurança para a região da Ásia-Pacífico, no sentido de contrabalançar a ascensão chinesa. O governo passou a liderar a Trans-Pacific Partnership como a pedra angular de sua política para a região, com o objetivo de gerar empregos e renda nos EUA. 
O Quadrennial Defense Review - QDR de 2014 e o National Security Strategy NSS de 2015 consubstanciam o redirecionamento em direção à Ásia-Pacífico como prioridade geoestratégica, visando contrabalançar o peso da China, em detrimento do Oriente Médio, mas sem deixar de participar dos demais tabuleiros da Eurásia. Ou seja, seguem fundamentais a participação e presença na Eurásia e suas subregiões, assim como na OTAN, num contexto de rivalidade interestatal pela disputa de poder global, mas mudando a área prioritária em razão de fatores conjunturais e estruturais, o que revela que os documentos estratégicos do governo Obama acompanham a visão geopolítica clássica presente em Brzezinski ou Kissinger.

Os NSS de 2010 e 2014 reafirmam a importância de preservar a superioridade militar dos EUA e sua capacidade de enfrentar múltiplas ameaças de nações, atores não estatais e Estados falidos, mas trazendo de volta a questão do multilateralismo, através de um "engajamento abrangente" sob a liderança estadunidense, e da importância do poder do ponto de vista moral (ou de um discurso ético legitimamente aceito), que teria sido deteriorado pelo unilateralismo do governo Bush. Os documentos deixam claro o comprometimento com o envolvimento na Eurásia, com a OTAN e os aliados na Ásia-Pacífico. Afirmam que as relações com os aliados europeus, especialmente da OTAN, devem ser fortalecidas e são importantes no campo econômico e da segurança, para deter "ameaças vitais" (USA, 2010a, p. 41). Sobre a Ásia, aponta que seu crescimento econômico significativo, assim como de seus centros emergentes, tem conectado seu futuro à prosperidade dos EUA, o que o leva a buscar um profundo engajamento na região, inclusive buscando um papel maior em arranjos multilaterais, como a ASEAN, APEC e TPP. Destaca as alianças bilaterais com Japão, Coreia do Sul, Austrália, Filipinas e Tailândia, sendo suas revitalizações estratégicas para a segurança e prosperidade na Ásia-Pacífico, levando em conta as tendências e desafios do século XXI. Nesse ponto, Japão e Coreia são destacados como países líderes e parceiros fundamentais para presença militar, integração regional, difusão da agenda de segurança e dos valores estadunidenses na região (USA, 2010a).

Os documentos QDR e NSS do governo Obama (USA, 2014; USA 2015) mostram uma preocupação central com a distribuição de poder global, especialmente diante da ascensão da China, mas fazendo referência também a Rússia, Índia, Brasil e África do Sul. O NSS observa a ascensão e maior participação internacional da China e da Índia, os países mais populosos do mundo, e também faz referência a "centros de influência emergentes" como o Brasil e a África do Sul. Mas observa a Rússia "emergindo" recentemente, e a necessidade de estabelecer uma relação 
cooperativa, especialmente por conta de seu arsenal nuclear e de sua relação com vizinhos. O NSS de 2010 observa que todos esses países, juntos, estão construindo maior influência e voz internacional. Tais preocupações refletem uma preocupação com o fortalecimento e as articulações no âmbito do BRICS. O QDR 2010 cita o desenvolvimento e os investimentos militares chineses como potenciais ameaças, o que fariam aumentar o número de interrogações quanto a suas intenções de longo prazo. Por fim, o documento aponta um conjunto de ações geoestratégicas dos EUA, em termos militares, para contrabalançar possíveis movimentos daqueles que identifica como potenciais contestadores de sua supremacia, nomeadamente, China e Rússia (USA, 2010b). Já no NSS de 2014, no contexto da crise política gerada na disputa pela Ucrânia e consequente invasão à Crimeia por parte da Rússia, aponta essa como uma ameaça à Europa, preocupando-se com a dependência energética europeia e ucraniana, e a necessidade de manter sanções e conter as agressões e violações à soberania. Sobre a questão energética, aparece nos NSSs a preocupação em buscar novas tecnologias para reduzir a dependência externa de petróleo. O discurso do governo Obama sempre esteve voltado para fontes alternativas e renováveis, para diminuir o déficit comercial e a dependência energética estadunidenses. No entanto, aborda também a questão do Oriente Médio, e sua relação com o acesso assegurado a energias fósseis para os EUA e seus aliados, como um tema de segurança energética (USA, 2010a).

Sobre a América, o documento Western Hemisphere Defense Policy Statement, do Departamento de Defesa, de 2012, refere-se às novas ameaças como "desafios complexos do século 21 " no campo da segurança e à necessidade de proliferar essa agenda por meio de ações bilaterais, organizações multilaterais (especialmente regionais), think tanks e pesquisas. Reforça também que as forças armadas dos países latino-americanos devem se dedicar ao combate às chamadas novas ameaças.

\section{Considerações finais}

Os documentos estratégicos analisados revelam uma continuidade na geoestratégia estadunidense pós Guerra Fria: uma presença permanente e de protagonismo na OTAN, com objetivo de manter o controle militar sobre a Europa Ocidental, avançar em direção à Rússia e à Ásia Central, especialmente buscando conter seu possível avanço e influência. Ainda, revela uma estratégia de promoção do equilíbrio de poder na Eurásia, em suas diferentes áreas, primeiro com maior 
ênfase no Oriente Médio e recentemente na Ásia-Pacífico, para contrabalançar a ascensão chinesa. A presença militar estadunidense no Oriente Médio mostra também um caráter permanente, por razões estratégicas, que lhe auferem poder de barganha frente aos aliados e capacidade de negar acesso aos rivais em momentos de crise política - no sentido da Doutrina Carter. Ao mesmo tempo, mantêm uma política de supremacia hemisférica. Ainda, a retórica sobre "novas ameaças" e a legitimidade interna e externa parecem importantes do ponto de vista de manter uma presença e capacidade de intervenção militar global, assim como altos gastos militares para o seu complexo industrial-militar, todos fundamentais para a liderança militar e tecnológica global e para a estratégica de manutenção da supremacia global dos EUA.

Assim as ações de Estado dos EUA e sua continuidade são influenciadas pelas concepções de Kissinger e de Brzezinski, que seguem a geopolítica clássica no sentido de apontar a Eurásia como o continente basilar para o equilíbrio e os rumos da política de poder global; e colocando os objetivos estratégicos acima de qualquer discussão sobre custos econômicos ou limites orçamentários. Para Brzezinski e Kissinger, a presença militar na OTAN, no Oriente Médio e no Sudeste da Ásia são irrevogáveis, visto que os EUA devem se preocupar com o equilíbrio de poder global, sendo esse o continente mais relevante. Vale ressaltar que qualquer discussão sobre limite orçamentário perderia relevância se fosse observado que os EUA emitem a moeda internacional sem lastro, não enfrentando limites nos seus gastos e endividamento, sustentados também em seu poder militar e tecnológico.

Embora a hegemonia hemisférica apareça como um consenso para todos os autores aqui abordados, as relações fundamentais para a geoestratégia dos EUA estão no eixo Leste-Oeste, entre os países do hemisfério norte.

É importante observar que, qualquer que tenha sido o partido na Presidência dos EUA no período analisado, com suas diferenças táticas, os objetivos geoestratégicos que prevaleceram, mostrando continuidade, foram os apontados por Kissinger ou Brzezinski, influenciados pela geopolítica clássica. E qualquer presidente que tente mudar isso enfrentará resistências e restrições dentro do próprio Estado.

No pós Guerra Fria, a atuação militar dos EUA na América Latina vem sendo mantida por meio de diversos instrumentos ${ }^{15}$, sob a retórica de prevenir e promover a capacidade de combate às novas ameaças (PADULA, 2015). Enquanto

15 Estabelecimento de bases operacionais (inclusive na Colômbia, próximas à Amazônia), ajuda econômica e militar (como o Andean Trade Promotion and Drug Eradication Act), staff talks, exercícios militares conjuntos, ações cívico-sociais, a reativação recente da sua IV Frota para o Atlântico Sul e comércio seletivo de armas. 
a atuação dos EUA, no "grande jogo" da Eurásia, segue as orientações dos seus documentos estratégicos, diante de um quadro de significativa complexidade, com a utilização de meios militares, geopolíticos e geoeconômicos, e midiáticos. Revela-se uma grande disputa entre EUA e seus aliados na OTAN, de um lado, e China e Rússia e seus aliados, do outro, que deve ter impacto determinante no futuro geopolítico global; sendo importante que sejam desenvolvidas pesquisas sobre os seus desdobramentos, incluindo destaque para a Organização da Cooperação de Xangai.

\section{Referências}

ANDERSON, P. A política externa norte-americana e seus teóricos. São Paulo: Boitempo, 2015.

BRZEZINSKI, Z. Game Plan..... Atlantic Monthly Press, 1986.

"The Group of Two that could change the world", Financial Times, January 13, 2009, 2009. Disponível em: <https://www.ft.com/content/d99369b8-e178-11ddafa0-0000779fd2ac. > .

. Strategic Vision. America and the crisis of Global Power. New York: Basic Books, 2012a.

. "Balancing the East, Upgrading the West - U.S. Grand Strategy in an Age of Upheaval”, In Foreign Affairs, January/February, 2012b.

BURNHAM, J. The Struggle for the World. New York: The John D Company, 1947.

HAMILTON, A. Federalist, 1787. Disponível em: < http://www.foundingfathers.info/ federalistpapers/hamilton.htm > .

HUNTINGTON, S. Who are we: the challenges to America's National Identity. London: Simon \& Schuster, 2005.

KAPLAN, R. A vingança da geografia. São Paulo: Elsevier, 2015.

KISSINGER, H. A Ordem Mundial. Editora Objetiva, 2015.

KISSINGER, H. Diplomacia. Lisboa: Gradiva, 1994.

. "The Interview: Henry Kissinger". National Interest, August 19, 2015.

"Interview to CBS". Face the Nation (Transcript). December 18, 2016a. Disponível em: < https://www.cbsnews.com/news/face-the-nation-transcript-conway-kissingerdonilon/ $>$.

. "Kissinger's vision on US-Russia Relations" (Kissinger's speech in Moscow). The National Interest, February 04, 2016b. Disponível em: < http://nationalinterest.org/ feature/kissingers-vision-us-russia-relations-15111 > . 
. "Kissinger: Russia-U.S. dialogue must focus on shared future, not conflict”. Russia Beyond, February, 2016c. Disponível em: < https://www.rbth.com/politics_and_ society/2016/02/04/henry-kissinger_565099>.

KLARE, M. Rising Powers, Shrinking Planet. New York: Penguin Books, 2008. Blood and oil. New York: Penguin Books, 2005.

MACKINDER, H. J. “The geographical pivot of history”. In The Geographical Journal, 23, p. 421-37, 1904.

MAHAN, A.T. The Influence of Sea Power Upon History 1660-1783. British Library, Historical Print Editions, 1890.

MEARSHEIMER, John, WALT, Stephen. “The Case for Offshore Balancing”. In Foreign Affairs, July/August. 2016.

NATO. NATO 2020: Assured Security; Dynamic Engagement, 2010. Disponível em: $<$ https://www.nato.int/cps/en/natohq/official_texts_63654.htm > .

PADULA, R. "A disputa pela agenda de segurança regional e o Conselho de Defesa SulAmericano”. In Revista da Escola de Guerra Naval, vol. 21, n. 2, p. 221-262, jul./ dez, 2015.

SPYKMAN, N. America's Strategy in World Politics. New York: Routledge, 1942.

USA. United States of America. National Military Strategy of the United States, 1991. Disponível em: < http://nssarchive.us/NSSR/1991.pdf > .

. A National Security Strategy of Engagement and Enlargement, 1994. Disponível em: < http://nssarchive.us/ > .

. A National Security Strategy of Engagement and Enlargement, 1996. Disponível em: < http://nssarchive.us/ > .

. National Security Strategy, 2002. Disponível em: < http://nssarchive.us/ > .

. National Security Strategy, 2006. Disponível em: < http://nssarchive.us/ > . . National Security Strategy, 2010a. Disponível em: < http://nssarchive.us/ > . . Quadrennial Defense Review, 2010b. Disponível em: < https://www.defense.gov/ Portals/1/features/defenseReviews/QDR/QDR_as_of_29JAN10_1600.pdf > .

. Western Hemisphere Defense Policy Statement, The Department of Defense (DoD), 2012. Disponível em: < https://www.hsdl.org/?abstract\&did = 723274 > .

. Quadrennial Defense Review, 2014. Disponível em: < http://archive.defense.gov/ pubs/2014_Quadrennial_Defense_Review.pdf > .

. National Security Strategy, 2015. Disponível em: < http://nssarchive.us/ > . 